\title{
Pancreatic Neoplasm
}

National Cancer Institute

\section{Source}

National Cancer Institute. Pancreatic Neoplasm. NCI Thesaurus. Code C3305.

A benign or malignant neoplasm involving the pancreas. 